\title{
Cytological Study of Palpable Breast Lump Presenting in Eastern Nepal
}

Singh $M^{1^{*}}$ Kafle $S U^{2}$ Jha $K K^{1}$

\section{Affiliation:}

1. Lecturer, Department of Pathology, Birat Medical College \& Teaching Hospital, Tankisinuwari-02, Morang Nepal

2. Associate Professor, Department of Pathology, Birat Medical College \& Teaching Hospital, Tankisinuwari-02, Morang Nepal

\section{ARTICLE INFO \\ Article History \\ Received : 28 Oct, 2016 \\ Accepted : 29 Nov, 2016 \\ Published : $20 \mathrm{Dec}, 2016$}

(c) Authors retain copyright and grant the journal right of first publication with the work simultaneously licensed under Creative Commons Attribution License CC - BY 4.0 that allows others to share the work with an acknowledgement of the work's authorship and initial publication in this journal.

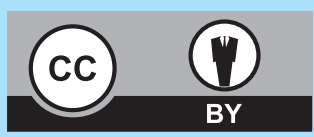

* Corresponding Author

Dr. Mrinalini Singh Lecturer Department of Pathology Birat Medical College \& Teaching Hospital

Tankisinuwari-02, Morang Nepal Email: guddisinghdas4@yahoo.co.in

\section{Citation}

Singh M, Kafle SU, Jha KK. Cytological Study of Palpable Breast Lump Presenting in Eastern Nepal. BJHS 2016; 1 (1) 1:27-32.

\section{ABSTRACT}

\section{Introduction}

Breast lump constitute significant proportion of surgical cases. It is necessary to distinguish between benign and malignant lesions for definite treatment. Fine needle aspiration cytology (FNAC) is widely adopted for the pathologic assessment because of its accuracy and ease of use.

\section{Objective}

The present study was done to find out the frequency of various patterns of breast lesion on FNAC and the common age-group in which the lesions occurs.

\section{Methodology}

This is a four years retrospective study carried out from December 2011 to January 2016. The 553 patients who presented with palpable breast lump, and have underwent FNAC irrespective of age and sex were included in the study. All the datas were collected from the patients record form. FNAC findings were correlated with the data from histopathology records to determine the sensitivity and specificity of FNAC.

\section{Results}

The majority of the patients were female and majority of lump was benign. Fibroadenoma was the most common lesion accounting for $32.18 \%$ of all lesions and most commonly occurring in age group between 21-30 years. Fibrocystic disease was second common benign lesion accounting for 30.56 also commonly accounting in the age group 21-30 years. Carcinoma breast was seen in $5.42 \%$ of cases $(30 / 553)$ occurring most commonly in the female patients above 30 years of age. Most common age group for gynaecomastia in male breast was $11-20$ years.

\section{Conclusion}

FNAC is a rapid and safe method for diagnosing palpable breast lump into benign and malignant categorizes and thus avoiding unnecessary surgery.

\section{KEY WORDS}

Breast lump, fibroadenoma, fibrocystic change, gynaecomastia 


\section{INTRODUCTION}

Benign as well as malignant breast lesions are quite common in Nepalese population. FNAC especially in developing counties is widely used as a reliable technique for preoperative evaluation of palpable breast lumps. The procedure of FNAC is safe, it is less time consuming and because of its low cost it does not cause unnecessary financial burden on patients. Breast lesions mainly present as lump. Most of the breast lumps are seen in women and the majority of the lumps are benign. But it is associated with stress and anxiety, in the patients because of the fear of cancer, compelling them to visit doctor. ${ }^{1,2}$

To differentiate benign from malignant lesions preoperatively is one of the major goals of FNAC for definite treatment., FNAC can also help in subtyping the various benign as well as malignant lesions. This is useful in further planning the treatment of patients and also helps to avoid unnecessary surgery.

The present study was carried out with aim of studying the frequency of various breast lesions on FNAC presenting in eastern region of Nepal and also to find out the common causes of breast lumps and the common age group in which they occur. Histopathological correlation was also done in the available cases.

\section{METHODOLOGY}

This is a retrospective study done in the pathology department of Birat Medical College and Sriram Diagnostic Laboratory, Biratnagar, Nepal. Demographic data including age, sex and clinical presentation were obtained from the patients requisite form. Also any other diagnostic findings like Mammography / ultrasonography (USG) were noted. All 553 patients who presented with breast lumps, irrespective of age and sex were included in the study. All the slides of the reported cases of FNAC and available histopathology reports were taken out and it was analyzed again by three independent pathologists. The FNAC slides were of both 95 $\%$ alcohol fixed Papanicolaou stain and air dried smears of May-Grunewald Giemsa stain. In lesions were pus was aspirated a single slide with Ziehl-Neelson (ZN) stain was also present for demonstration of acid fast bacilli. The lesions were categorized as benign and malignant.

The benign lesions were further sub categorized wherever possible under specific pathologic diagnosis. The benign lesions which could not be classified under specific disease were categorized as 'Benign Breast lesions only'. The cases which were doubtful for malignancy on cytologic examination were categorized as 'Suspicious for Carcinoma Findings of FNAC were correlated with histopathology slides which were H\&E stain. Sensitivity and specificity were calculated using standard statistical methods.

\section{RESULTS}

Out of 553 patients as soon in table 1 and 2, 26 (4.71\%) were male and 527 (95.29\%) were female. Maximum patients were in the age group 21-30 years.

\section{Table 1: Show FNA diagnosis of breast lumps}

\begin{tabular}{|c|c|c|c|}
\hline S.No. & Types of Lesion & No. of Cases $(n=533)$ & Percentage \\
\hline 1 & Fibroadenoma & 178 & 32.18 \\
\hline 2 & Fibrocystic Change & 169 & 30.56 \\
\hline 3 & Mastitis/Breast Abscess/Granulomatous Lesion & 86 & 15.55 \\
\hline 4 & Phyllodes Tumor & 2 & 0.36 \\
\hline 5 & Galactocele & 11 & 1.98 \\
\hline 6 & Tuberculosis Breast & 2 & 0.36 \\
\hline 7 & Fat Necrosis & 1 & 0.18 \\
\hline 8 & Reactive Lymphadenitis & 1 & 0.18 \\
\hline 9 & Atypical Ductal Hyperplasis & 2 & 0.36 \\
\hline 10 & Hemangioma & 1 & 0.18 \\
\hline 11 & Epidermal Inclusion Cyst/Cystic Breast Lesion & 7 & 1.26 \\
\hline 12 & Duct Ectasia & 1 & 0.18 \\
\hline 13 & Hypertrophic Fat Tissue & 1 & 0.18 \\
\hline \multirow[t]{2}{*}{14} & Benign Breast Disease Which Could Not be Categorized in & & \\
\hline & Specific Entity. & 21 & 3.79 \\
\hline 15 & Suspicious of Carcinoma & 4 & 0.72 \\
\hline 16 & Carcinoma Breast & 30 & 5.42 \\
\hline 17 & Inadequate Sampe & 10 & 1.8 \\
\hline 18 & Gynaecomastia & 26 & 4.7 \\
\hline
\end{tabular}


Table 2: Show frequency of FNAC diagnosis of breast lesions In various age (years) groups

\begin{tabular}{|c|c|c|c|c|c|c|c|c|c|}
\hline S.No. & Types of Lesion & $1-10$ & $11-20$ & $21-30$ & $31-40$ & $41-50$ & $51-60$ & $\begin{array}{c}\text { Above } \\
>61\end{array}$ & Total \\
\hline 1 & Fibroadenoma & 2 & 43 & 77 & 42 & 9 & 5 & 0 & 178 \\
\hline 2 & Fibrocystic Change & 1 & 15 & 77 & 54 & 18 & 2 & 2 & 169 \\
\hline \multirow[t]{3}{*}{3} & Mastitis/Breast Abscess/ & & & & & & & & \\
\hline & Granulomatous Lesion/ & & & & & & & & \\
\hline & Subareolar Abscess & 0 & 8 & 29 & 32 & 10 & 6 & 1 & 86 \\
\hline 4 & Phyllodes Tumor & 0 & 0 & 1 & 1 & 0 & 0 & 0 & 2 \\
\hline 5 & Galactocele & 0 & 3 & 6 & 2 & 0 & 0 & 0 & 11 \\
\hline 6 & Tuberculosis Breast & 0 & 1 & 1 & 0 & 0 & 0 & 0 & 2 \\
\hline 7 & Fatnecrosis & 0 & 0 & 0 & 1 & 0 & 0 & 0 & 1 \\
\hline 8 & Reactive Lymphadenitis & 0 & 0 & 1 & 0 & 0 & 0 & 0 & 1 \\
\hline 9 & Atypical Ductal Hyperplasia & 0 & 0 & 0 & 1 & 0 & 1 & 0 & 2 \\
\hline 10 & Hemangioma & 0 & 0 & 0 & 1 & 0 & 0 & 0 & 1 \\
\hline \multirow[t]{2}{*}{11} & Epidermal Inclusion & & & & & & & & \\
\hline & Cyst/Cystic Breast Lesion & 0 & 0 & 1 & 5 & 2 & 0 & 0 & 8 \\
\hline 12 & Ductectasia & 0 & 0 & 0 & 0 & 1 & 0 & 0 & 1 \\
\hline 13 & Hyper Trophic Fat Tissue & 0 & 0 & 1 & 0 & 0 & 0 & 0 & 1 \\
\hline 14 & Benign Breast Disease & 2 & 1 & 10 & 6 & 2 & 0 & 0 & 21 \\
\hline 15 & Suspicious of Carcinoma & 0 & 0 & 0 & 1 & 1 & 2 & 0 & 4 \\
\hline 16 & Carcinoma Breast & 0 & 0 & 2 & 11 & 10 & 4 & 3 & 30 \\
\hline 17 & Inadequate Sampe & 0 & 0 & 0 & 2 & 8 & 0 & 0 & 10 \\
\hline 18 & Gynaecomastia & 0 & 8 & 3 & 5 & 1 & 3 & 6 & 26 \\
\hline
\end{tabular}

The 515 (93.12\%) patients had benign breast lumps and 30 patients $(5.42 \%)$ had malignant breast lumps $4(0.72 \%)$ cases were suspicious of carcinoma. In $10(1.8 \%)$ cases the sample was inadequate and so no definite opinion was possible.

The cytological spectrum of various benign breast lesions encountered in the present study shows that of total 515 cases, 494 cases could be subcategorized as various benign lesions such as Fibroadenoma accounting for 178 (32.18\%), fibrocystic changes (figure 1) 169 (30.56\%), Mastitis / Breast Abscess including Granulomatous Lesion $86(15.55 \%)$, Phyllodes Tumor 2 (0.36\%), Galactocele 11 (1.98\%), Tuberculosis breast with AFB positive. 2 (0.36\%), Fat necrosis 1 (0.18\%), Reactive lymphadenitis 1 (0.18\%), Hemangioma $1(0.18 \%)$, Epidermal Inclusion Cyst / Cystic Breast Lesion 7 (1.26\%), Duct Ectasia 1 (0.18\%), Hypertrophic fat tissue $1(0.18 \%)$. However 21 (3.79\%) cases were diagnosed as Benign Breast Disease only as it could not be further sub categorized into specific cytologic diagnosis. 26 cases (4.7\%) were from male breast all of them were diagnosed as gynaecomastia. In 10 (1.8\%) of the cases the sample were inadequate and no definite opinion was possible. So repeat FNAC or excision biopsy were advised in these cases.

Figure 1: Papanicolaou stain of fibrocystic changes with clusters of apocrine cells . $x 4 X$

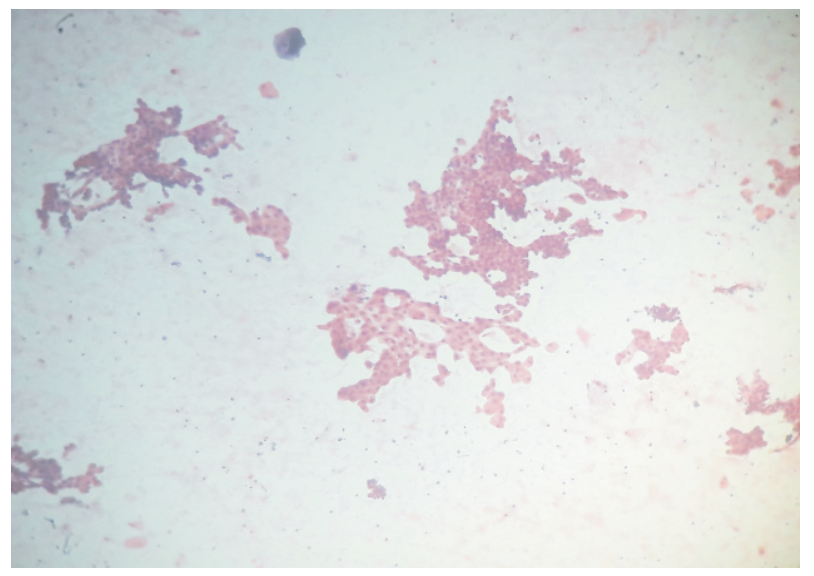


On the other hand, the cytological spectrum of various malignant lesions encountered in the present study shows that 30 cases (5.42\%) were successfully labeled as carcinoma (figure 2 ) where as 4 cases $(0.72 \%)$ were labelled as suspicious of malignant tumor in which histopathology was advised. Two $(0.36 \%)$ of the cases showed microscopy features of Atypical Ductal Hyperplasia.

\section{Figure 2: Papanicolaou stain of carcinoma breast (x4X)}

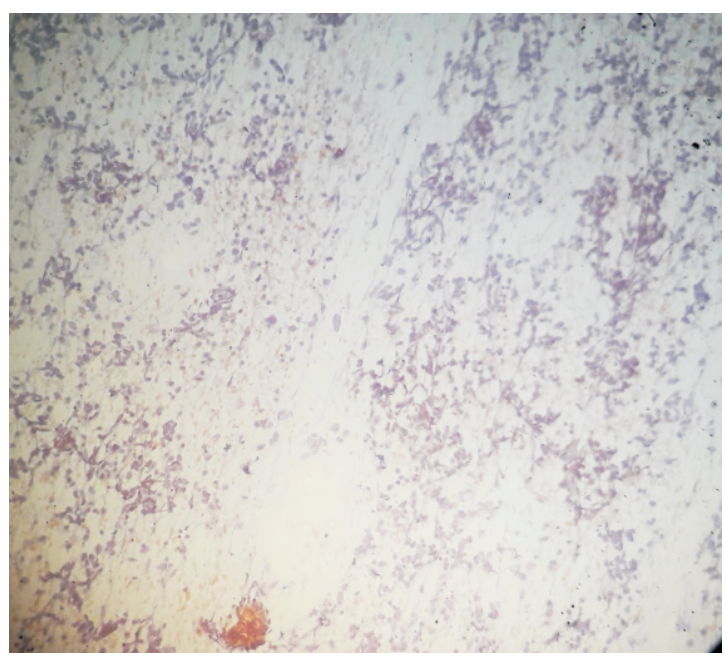

Out of 553 cases of cytopathology study, 61 cases were available for histopathological correlation. Out of 56 cytological benign cases, 53 were confirmed as benign on histopathology but 3 cases turned out to be malignant. (figure 3 show histopathology of malignant tumor) Therefore the sensitivity of FNAC was found $37 \%$ a bit less as compared to other studies. However the specificity was $100 \%$ and positive predictive value was $100 \%$.

The 3 cases diagnosed as suspicious of malignancy and 2 cases of Atypical Ductal Hyperplasia turned out to be malignant on histopathological examination.

Figure 3: Histopathology of infiltrating ductal carcinoma breast with comedo necrosis H \& E stain $\mathrm{x} 10 \mathrm{X}$

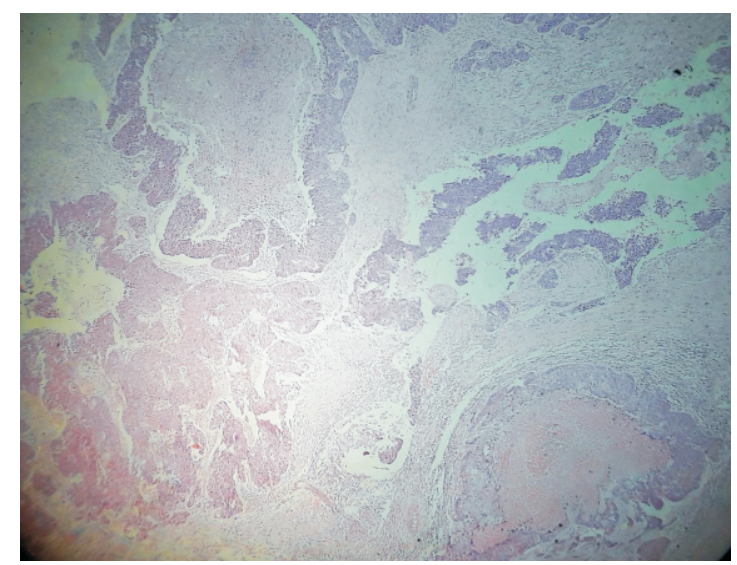

\section{DISCUSSION}

FNAC of the breast lump is an accepted and established method to determine high degree of accuracy., ${ }^{5,6,7}$ Lumps in the breasts may be benign or malignant. Preoperative diagnosis helps in planning the correct surgical and therapeutic treatment. The present study showed that the benign lesions of breast were the common lesions. We have found that majority of the benign lesions can be further subclassified when the material is adequate. In the present study, fibroadenoma was the most common benign lesion. FNAC diagnosis of fibroadenoma was made on diagnostic triad of cellular smears with bimodal pattern, numerous single bare bipolar nuclei and fragments of fibromyxoid stroma. Second most common benign breast lesion we encountered was fibrocystic change. Fibrocystic change is not a specific cytological diagnosis. Cytology samples must be evaluated in the context of clinical and mammography findings. Some of these lesions simulate carcinoma clinically, radiologically, and microscopically. ${ }^{9}$ FNAC smears showed many macrophages and small clusters of apocrine cells with or without chronic inflammatory cells. Small clusters of ductal epithelial cells without atypia were also seen. We have reported 86 (15.55\%) cases of mastitis including subareolar abscess. Most of the cases yielded pus which on microscopy revealed many polymorphs as well as macrophages. The clinical features of mastitis can be confused with breast cancer. So early diagnosis and treatment is necessary. ${ }^{10,11,12}$ Tuberculosis of breast is a rare disease with reported incidence varying from $3-4.5 \% .{ }^{13} \mathrm{We}$ have encountered two cases of tuberculosis which showed positivity for AFB stain. We have also seen two cases of benign Phyllodes tumor in our study. Definitive diagnosis was given based on predominance of stromal components, fragments of highly cellular myxoid stroma and numerous single spindle shaped nuclei. Nuclear atypia and mitotic figures were absent. All our patients who showed features of galactocele were lactating mother. All the patients who showed features of cystic lesion yielded fluidy aspirate on FNAC. None of the cases showed atypical cells. One case of reactive lymphadenitis was seen. Here the lump was near to axillary region. One case of fat necrosis revealed previous history of trauma. Hypertrophic fat tissue is difficult to differentiate on FNAC, since normal breast also show fat tissue. The diagnosis was confirmed after the radiological examination. Similarly the case of Hemangioma yielded only blood which was also confirmed after ultrasound examination. Fibroadenoma (32. $18 \%$ ) followed by fibrocystic changes (30.56\%) and mastitis / breast abscess (15.55\%) were the most common breast lesions on cytology which is similar to study done by 
Domingues et al $\left(34.49 \%, 32.17 \%\right.$ and $1.55 \%$ respectively). ${ }^{14}$ Where as in study by Tiwari and Qasin etal (Fibroadenoma $56.25 \%$ and $82.14 \%$ ); followed by mastitis / breast abscess (15.55\%) and fibrocystic disease (30.56\%) were the most common breast lesion. ${ }^{15,16}$ In most of the above mentioned series, fibroadenomas had the most common age of presentation 21-30 years. Thus the present study is in concordance with the studies available in the literature. In the present study maximum number of benign cases are seen in the age group ranging from $11-40$ years. This findings is similar to study by Klemka et al and Rocha et al who found maximum cytological benign cases in the age-group 15-44 years and $11-40$ years respectively. ${ }^{17,18}$ In the present study cytologically suspicious lesions were in the age group 31-60 years. Mac Intosh et al and Roch et al had reported maximum number of suspicious cases in the age group 33-75 years and 31-75 years respectively. ${ }^{19,18}$ This is nearby similar to our study. Gynaecomastia is a benign proliferation of male breast. Gynaecomastia develop as a response to increase estrogen level. In our study increase incidence of Gynaecomastia is seen in teenage boy which may be due to hormonal imbalance. Cancers in male breasts are rare. In our study we did not find a case of carcinoma in male breast. Benign breast lesions which could not be subcategorized into a specific lesion on cytology revealed a low cell yield. These cases on aspiration showed ductal epithelial cells with overlying myoepithelial cells and scattered single bare bipolar nuclei, in the absence of fibromyxoid stromal fragments, apocrine cells and macrophages. None of these cases show features of nuclear atypia. Ten $(1.8 \%)$ cases were inadequate for definite diagnosis. We found that inadequate aspiration was the most common cause in these cases. The aspiration is influenced by the nature of the lesion and the experience of the pathologist. We can reduce the rate of inadequate sampling by reaspiration under ultrasound guidance. Three of our benign cases on FNAC turned out to be malignant on histopathological examinations. The reason for this could be low cellularity of the smear and the tumor cells revealing mild nuclear atypia.

In our study maximum number of carcinoma breast was seen in between age group 31-50 years. We could not sub classify malignant tumors on specific subtype on FNAC. It may be because most of our tumors appear poorly diffentiated and there is a lack of available resources like Immunocytochemistry. The average age of occurrence of breast cancer is women early as compared to data reported on USA patients. ${ }^{20}$ The reason for this needs to be further studied. A similar pattern of shift of cancer towards younger women is shown in a study conducted by Borovanova. ${ }^{21}$ In the present study, all the cytological diagnosed malignant cases was confirmed as malignant on subsequent histopathological examinations. So, in our study, a $100 \%$ cyto histopathological correlation was observed for malignant lesions. Zhang Qin et al., AZ and Mohammed et al had also observed the same results in their studies. ${ }^{22,23}$

\section{CONCLUSION}

Benign breast lesions are more common than the malignant lesions. Fibroadenoma and fibrocystic disease are more common benign lesion occurring in between 21-30 years of age. Many times it is mention that "Is FNAC adequate for diagnosis" ? In the present study there was no false positive case for malignancy as confirmed by histopathology. So we can assure the patient who has to undergo surgery for cancer based on FNAC report. But we have seen that FNAC has shown low sensitivity show triple assessment (which assigns a score to a breast lesion by taking into consideration the clinical diagnosis, mammography diagnosis and the cytology diagnosis together and not any one diagnosis in isolation) is must.

\section{RECOMMENDATIONS}

In this study, we have realized that one cannot overlook the importance of clinical and radiological assessment for diagnosing breast lumps. This is especially so in cases that is labelled on cytology as atypical or suspicious. Clinical breast examination and mammography screening in female subjects should be encouraged in developing countries for early detection of breast carcinoma.

\section{LIMITATIONS OF THE STUDY}

Out of 553 cases of FNAC, only 61 cases were available for histopathological correlation. The sensitivity and specificity is based on small sample size. The findings may not be valid but the findings are comparable with other studies were sample size is high. The inter-observer subjectivity that exists during interpretation of smears was always considered, and this was reduced by agreement of the pathologists on diagnostic cytomorphologic criteria.

\section{ACKNOWLEDGEMENTS}

The author would like to thank Dr Surya B. Parajuli, lecturer in Department of Community Medicine, Birat Medical College \& Teching Hospital and Mr. Birendra Kumar Roy (Lab technician) for their help in data management.

\section{CONFLICT OF INTEREST}

None 


\section{REFERENCES}

1. Waqar AJ, Zada N, Israr M. Comparison of FNAC and core needle biopsy for evaluating breast lumps. JCPSP 2002; 12:686-8.

2. Samee WO. Benign breast disorders. Surg Int. 1996;34:136-9

3. Vaidyanathan L, Barnard K, Elnicki DM. Benign breast disease: When to treat, when to reassure, when to refer. Cleve Clin $J$ Med. 2002; 69:425-32.

4. Guray M, Sahin A A. Benign breast diseases: Classification, diagnosis, and management. Oncologist. 2006; 11:435-49.

5. Purasiri P, Abdalla M, Heys SD, Ah-See AK, McKean ME, Gilbert FJ, Needham G, Deans HE and Eremin O.A novel diagnostic index for use in the breast clinic. J JR Coll Surg Edinb 1996;41: 30-4

6. Kaufman Z, Shpitz B, Shapiro M, Rona R, Lew S, Dinbar A. Triple approach in the diagnosis of dominant breast masses: combined physical examination, mammography and fine-needle aspiration. J Surg Oncol .1994; 56:254-7

7. Dehn TCB, Clarke J, Dixon JM, Crucioli V, Greenall MJ, Lee ECG Fine needle aspiration cytology, with immediate reporting in the outpatient diagnosis of breast disease. Ann R Coll Surg Eng 1987; 69: 280-2

8. Dixon MJ, Anderson TJ, Lamb J, Forest AMP. Fine needle aspiration cytology, in relationships to clinical examination and mammography in the diagnosis of a solid breast mass. Br J Surg 1984; 71:593-6 aspiration. J Surg Oncol 1994; 56: 254-7

9. Marshall LM, Hunter DJ, Connolly JL, Schnitt SJ, Byrne C, London SJ, et al. Risk of breast cancer associated with atypical hyperplasia of lobular and ductal types. Cancer Epidemiol Biomarkers Prev. 1997;6:297-301

10. Foxman B, D'Arcy H, Gillespie B, Bobo JK, Schwartz K. Lactation mastitis: Occurrence and medical management among 946 breast feeding women in the United States. Am J Epidemiol. 2002;155:103-14.

11. Michie C, Lockie F, Lynn W. The challenge of mastitis. Arch Dis Child. 2003;88:818-21.
12. Dener C, Inam A. Breast abscesses in lactating women. World J Surg. 2003;27:130-3.

13. Shinde SR, Chanawarkar RY,Deshmukh SP.Tuberculosis of the breast masquerading as carcinoma : A study of 100 patients.World J Surg. 1995; 19:379-8

14. Domínguez F, Riera JR, Tojo S, Junco P. Fine needle aspiration of breast masses. An analysis of 1,398 patients in a community hospital. Acta Cytol 1997; 41:341-7

15. Tiwari M. Role of fine needle aspiration cytology in diagnosis of breast lumps. Kathmandu Univ Med J (KUMJ) 2007; 5:215-7.

16. Qasim M, Ali J, Akbar SA, Mustafa S. Lump breast: Role of FNAC in diagnosis. Prof Med J 2009;16:235-8.

17. Khemka A, Chakrabarti N, Shah S, Patel V. Palpable breast lumps: Fine - needle aspiration cytology versus histopathology: A correlation of diagnostic accuracy. Internet J Surg 2009;18:

18. Rocha PD, Nadkarni NS, Menezes S. Fine needle aspiration biopsy of breast lesions and histopathologic histopathology: a correlation of diagnostic accuracy. Internet J Surg, 18, 1.

19. Maclntosh RF, Merrimen JL, Barnes PJ. Application of the probabilistic approach to reporting breast fine needle aspiration in males. Acta Cytol 2008; 52:530-4

20. Parkin DM, Whelan SL, Ferlay J, Storm H: Cancer Incidence in Five Continents Vol.VIII. International Agency for research on Cancer [IARC], Lyon, France, IARC Scientific Publication No. 155.

21. Borovanova T, Soucek P: Breast cancer: An overview of factors affecting the onset and development of the disease. Cancer. Singapore Med J 1999; 40(09): 123-123.

22. Zhang Qin, Nie Shigui, Chen Yuhua, Zhou Limei . Fine Needle Aspiration Cytology of Breast Lesions: Analysis of 323 Cases. The Chinese-German Journal of Clinical Oncology, 2004; 3(3): 172-74.

23. Mohammad AZ, Edino ST, Ochicha O, Alhassan SU. Value of fine needle aspiration biopsy in preoperative diagnosis of palpable breast lumps in resource-poor countries: a Nigerian experience. Annals of African Medicine, 2005; 4(1): 19-22 